\title{
Child marriage and maternal health risks among young mothers in Gombi, Adamawa State, Nigeria: implications for mortality, entitlements and freedoms.
}

\author{
Olaide Adedokun ${ }^{1}$, Oluwagbemiga Adeyemi², Cholli Dauda ${ }^{1}$
}

1. Lagos State University, Ojo Lagos Nigeria, Department of Sociology

2. Federal University, Oye-Ekiti Nigeria, Department of Demography and Social Statistics

\begin{abstract}
:
Background: Efforts toward liberation of the girl-child from the shackles of early marriage have continued to be resisted through tradition, culture and religion in some parts of Nigeria.

Objective: This study therefore examines the maternal health implications of early marriage on young mothers in the study area. Methods: Multistage sampling technique was employed to obtained data from 200 young mothers aged 15-24 years who married before aged 16 years.

Findings: The study reveals that more than $60 \%$ had only primary education while more than $70 \%$ had experienced complications before or after childbirth. Age at first marriage, current age, level of education and household decision-making significantly influence $(\mathrm{P}<0.005)$ maternal health risks in the study area. The study establishes that respondents in age group 15-19 years are 1.234 times more likely to experience complications when compared with the reference category 20-24 years. Entitlements and freedom that are highly relevant to reduction of maternal mortality, provided by international treaties are inaccessible to young women in the study area.
\end{abstract}

Conclusion: Strategies to end child marriage in the study area should include mass and compulsory education of girls, provision of other options to early marriage and childbearing and involvement of fathers in preventing and ending the practice.

Keywords: Child marriage, maternal health risks, Nigeria, mortality, entitlements and freedoms.

DOI: http://dx.doi.org/10.4314/ahs.v16i4.15

Cite as: Adedokun O, Adeyemi O, Dauda C. Child marriage and maternal health risks among young mothers in Gombi, Adamawa State, Nigeria: implications for mortality, entitlements and freedoms. Afri Health Sci 2016;16(4): 986-999. bttp://dx.doi.org/10.4314/abs.v16i4.15

\section{Introduction}

Child marriage, referring to a marriage of a young person less than 18 years is still widely practiced in many parts of the World and predominantly affects girls. It is estimated that, if nothing changes, a 100 million young girls aged 15 years or less will be married within the present decade ${ }^{1}$. Regional estimates of its occurrence for girls include $48 \%$ in Southern Asia, 42\% in Africa and 29\% in Latin America and the Caribbean ${ }^{2,3}$ with wide differentials across the countries.

In the West African sub-region, the proportions of girls affected vary from 28\% - 43\% (Ghana, Togo, Cote d'Ivoire, Senegal, Benin, Nigeria) to $60-80 \%$ (Burkina Faso, Guinea, Mali, Chad and Niger).

In Nigeria, the practice of child marriage is deeply entrenched in tradition, culture and religion and the country has one of the highest rates of child marriage in the world,

\section{Corresponding author:}

Oluwagbemiga Adeyemi,

Federal University, Oye-Ekiti Nigeria,

Department of Demography and social statistics.

Email: gbemibola@gmail.com

African Health Sciences Vol 16 Issue 4, December, 2016 with estimated $42 \%$ of girls married before 18 years; and while this is found among many ethnic groups across the country, its predominance is clearly in the Northern part of the country ${ }^{4}$. While nation-wide, $20 \%$ of girls are married by age 15 and $40 \%$ are married by age 18 , child marriage is extremely prevalent in some regions such as among the predominantly Mus-lim Hausa-Fulani of the Northwest and North-East (of which Gombi is a part) where $48 \%$ of girls are married by age 15 , and $78 \%$ are married by age $18^{5,4}$. While average age at first marriage is 17 years nationwide, average age of marriage for girls is just over 11 years in Kebbi State and about 15 years in most other parts of Northern Nigeria. Among the Yorubas, made up of a mixture of Christians and Muslims in the South-West, child-marriages are no longer arranged and for the Igbo in the South-East that are predominantly Christians, the practice has declined considerably and restricted to few communities ${ }^{6}$ and situations where pregnant teen-agers are forcefully married off, to prevent family shame or restore honour ${ }^{6}$.

The reasons for child marriage are based on a mix of cultural, social, economic and religious factors. Poverty is 
observed to be at the core of decisions and practices related to early marriage, more in low-income societies than in their high-income counterparts, as they lack resources to support healthy alternatives for girls, such as prolonged schooling and skill acquisition to secure their future. The girls in turn have higher chances of being poor and remaining poor and of facing serious social and health consequences inimical to their personal growth and development. A study ${ }^{8}$ makes it clear that the widespread practice of child marriage makes it increasingly difficult for families to escape poverty in the developing world, thereby undermining critical international efforts to fight poverty, HIV/AIDS and other development challenges, and making huge investments in development assistance less effective. It is therefore very costly in terms of the consequences for these societies.

Girls who marry early are more likely to experience abuse and violence than others, with inevitable psychological as well as physical consequences. Studies indicate that women who marry at young ages are more likely to believe the justification for wife battering as a corrective measure and therefore acceptable for a husband to do so and are therefore more likely to experience and accept domestic violence themselves ${ }^{9,10,11}$. Child marriage for girls often means a confinement to a helpless lifetime of domestic and sexual subservience.

The psycho-social requirements of marriage (family and wife-mates politics and diplomacy) are often beyond child brides who are largely unprepared for their roles in complex family settings. Young brides are more often than not subjected to forms of abuse such as psychological trauma, domestic violence, forced sexual acts, marital rape by the husband and in-laws and subjected to domestic slavery, given her position as the young wife. Evidences of the links of early marriage with divorce, abandonment, separation, widowhood and denial of property rights abound in contemporary literature ${ }^{12}$.

Child marriage is widely and globally regarded as a surviving form of social discrimination and is challenged by the Nigerian constitution and several human rights laws. In the last Century, particularly, intense global opposition to child marriage has deepened and the concerns are expressed in various conventions and charters.

Under the Nigerian Law, the concept of the child is based exclusively on calendar age. The legal age at marriage is
21 years and anyone under this age is considered a minor and would require a parental consent before legally entering into a marriage in the country ${ }^{13}$. The rights of the girl-child in Nigeria are protected by a legal framework, including national laws and international and regional conventions which the country has ratified. The persistence of the practice of child marriage has been linked to lack of sufficient political will to engage the problem. In many countries, and despite the ratification of the international treaties and agreements, existing laws against child marriage are not enforced or upheld and sanctions are either not clearly spelt out or enforced at all ${ }^{14}$.

However, it is evident that the key national and international instruments that challenge child marriage focus on age, consent, equality within marriage, personal and property rights of women. The study therefore examines the implications of child marriage on maternal health and freedom.

\section{Data and methods}

The study was conducted in Gombi LGA in Adamawa State of Nigeria which is one of the twenty one LGAs in the state. The TRF is 6.7 while the mean number of children ever born to women of aged 40-49 is 7.1. Women in the reproductive age group 15-49 years are 32,527 ( National Population Commission,2010). The Gombi LGA has a population of 146,429 (Population Census, 2006). The LGA is made up of Gombi and other surrounding villages such as Fota, Fadchi, Walawal, Garkida, Guyaku, Balwhona, Wushipra, Gaanda, Lala, Bokki, Tsakuwa, Gudawi, Gombi, Ladiel, Fadchi, Kwallamba, Misamba and Ferwumarah. The unique characteristics of these villages include common language, religious beliefs and cultural practices which make the LGA homogeneous in nature. The study was carried out in rural areas.

Qualitative and quantitative methods were used for data gathering. For quantitative data, the structured Questionnaire was used while Focus Group Discussion (FGD) and In-depth interview methods were used for the collection of qualitative data.

Two Hundred (200) copies of questionnaire were administered. Stratified sampling technique was employed to select the sample for the study. The study area was stratified with the listing of the villages and eleven of the enlisted villages were randomly selected. The selection constitutes $50 \%$ of the total villages in the study area it will also make the study representative of the study population. From

African Health Sciences Vol 16 Issue 4, December, 2016 
the selected villages, houses were randomly selected using the National Population Commission (NPC) house numbering. From the selected houses young women aged 15-24 years who married before age 16 years and have had at least one child were interviewed using the specially designed questionnaire (there was a recall question). The questionnaire was pre-tested for validity and reliability of the instrument.

The reliability test was conducted before the administration of the questionnaire. In all, 200 questionnaires were correctly filled and analyzed for the study seven (7) were discarded. The information collected covered the socio-demographic characteristics, reproductive health issues, child bearing, sexual behaviour (questions on sexual behaviour were adapted from NDHS 2008), factors influencing child marriage in the study area and the risks of early marriage and childbearing. Six (6) Focus Group Discussions were held (50 discussants were selected across different socio-economic strata within the selected villages) to elicit information on traditional expectations regarding sexuality, impact of early marriage on well-being and consequences of early marriage. The participants were those in reproductive age 15-49 years who had at least a child as at the time of the survey. Sturctured interview guide was used for the FGDs. One focus group discussion each was carried out in six of the villages selected for the quantitative study. The FGDs were conducted by two trained research assistants from the state who are conversant with the culture and language of the people but not from the local government. Information provided was strictly maintained and the real names of the respondents were not used for the study. Issues about traditional expectations regarding sexuality, women's right regarding marriage, reactions to infected partners, and the extent to which men have control over sexuality. In-depth interviews were also conducted among 12 stakeholders (two each from health workers, community leaders, religious leaders, market women and traditional health workers. They were selected across the selected villages) in the study area. The exercise covered areas like: issues of child marriage, factors influencing child marriage, girl child education, sexual rights and choices in the community, and common maternal health risks. For each of the session of the FGDs and IDI, two trained research assistants were used (one served as note taker while the other RA served as moderator). The discussions (notes taken from each of the sessions) from the FGDs and IDIs were transcribed and translated verbatim. Analysis involved

African Health Sciences Vol 16 Issue 4, December, 2016 developing a system of indexing the data into sets of categories or codes that provided structure to the data based on the research objectives and the topic included in the questions guide. A qualitative software ZY-index software package for ethnographic data was used for textual data analysis. This does not allow the use of percentages and statistical analysis. Some striking expressions were for verbatim reporting. Data from qualitative survey have been extensively used inthis paper to validate quantitative analysis where and when necessary.

The quantitative data collected from this survey were subjected to three levels of analysis. The first level involves an examination of the distribution of the respondents according to selected characteristics. This is because the behaviour of individuals in society is, to a large extent, determined by their personal characteristics as well as those of the environment in which they live. For this reason, it is expected that child marriage will be greatly determined by background characteristics such as education, age, marital status, type of marital union and reproductive health decision making. To this end, simple percentages were employed to describe these variables. The second level involves the examination of the pattern of relationship between the dependent variables i.e. child marriage and other independent variables such as perceived risks of HIV, maternal health risks, reproductive decision making and antenatal care. The third level of the analysis involves the use of Logistic Regression techniques to show the effect of the relationship between the dependent variable (e.g. ever experienced pregnancy complications, yes $=1$, and no $=2$ ) and other independent variables (such as income, occupation, education, reproductive decision making. On ethical consideration, consent forms were administered to all the participants those who could read were asked to sign the consent forms while those who could not thumb printed the consent form. These forms were strictly kept by the researchers

\section{Findings \\ Socio-demographic characteristics}

Majority of the respondents $((72.5 \%)$ were in the $20-24 \mathrm{yrs}$ age cohort and had little exposure to formal education as $60 \%$ had attended a primary school while $30 \%$ had opportunities to attend and complete secondary school education. All the respondents were young mothers who married early at various ages before 16 years of age and had been married less than 5years (45.0\%), 5-9 years $(50.0 \%)$ and few $(5.0 \%)$ for more than 10 years. Some of 
the respondents were engaged in farming (41\%), trading $(15.5 \%)$, salaried workers in the local administrative offices while about one in every three $(35.0 \%)$ was a full-time housewife. They were more Muslims (59.0\%) than Christians $(41.0 \%)$. Estimated incomes of respondents reveal that more than half $(55.0 \%)$ earned less than N15, 000.00 $(\$ 100)$ per month, about a third $(35 \%)$ earned between N20, 000.00-N40, 000.00 (\$250) per month while $20 \%$ of the respondents earned more than this per month (Table $1)$.

Table 1: Percentage distribution of respondents' socio-demographic characteristics

\begin{tabular}{|c|c|c|c|}
\hline \begin{tabular}{|l} 
Variables \\
\end{tabular} & & Frequency & Percentage (\%) \\
\hline \multicolumn{4}{|l|}{ AGE } \\
\hline \begin{tabular}{|l|}
$15-19$ \\
\end{tabular} & & 55 & 27.5 \\
\hline $20-24$ & & 145 & 72.5 \\
\hline Total & & & 100.0 \\
\hline \multicolumn{4}{|l|}{ OCCUPATION } \\
\hline Farming & & 82 & 41.0 \\
\hline Trading & & 31 & 15.5 \\
\hline Civil Servant & & 17 & 13.5 \\
\hline House Wife & & 70 & 35.0 \\
\hline Total & & 200 & 100 \\
\hline \multicolumn{4}{|c|}{ Highest Level of education Attained } \\
\hline Primary Completed & & 64 & 32 \\
\hline Primary & Non- & 56 & 28 \\
\hline Completed & & & \\
\hline Secondary & & 60 & 30 \\
\hline $\begin{array}{l}\text { Post secondary } \\
\text { Total }\end{array}$ & & 20 & 10 \\
\hline \multicolumn{4}{|l|}{ Religious affiliation } \\
\hline Christians & & 82 & 41.0 \\
\hline Muslims & & 118 & 59.0 \\
\hline Total & & 273 & 100.0 \\
\hline $\begin{array}{l}\text { ESTIMATED } \\
\text { INCOME }\end{array}$ & $\mathbb{N} \quad$ per & 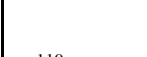 & \\
\hline month) & & 110 & (55.0 \\
\hline 10,000..00-19000.00 & & 70 & 35.0 \\
\hline 20000.00-40,000.00 & & 20 & 10 \\
\hline Above 40,000.00 & & 200 & 100 \\
\hline Total & & & \\
\hline \multicolumn{4}{|c|}{\begin{tabular}{|l} 
DURATION OF MARRIAGE (yrs) \\
\end{tabular}} \\
\hline Less than 5 & & 90 & 45.0 \\
\hline s-9 & & 100 & so.o \\
\hline $10 \&$ above & & 10 & 5.0 \\
\hline Total & & 200 & $\mid 100.0$ \\
\hline
\end{tabular}

The respondents weretherefore young mothers characterized by little education, largely informal sector engagement, low income, early marriage and rural residences.

\section{Family and marriage}

Early marriage for girls was still generally favoured to protect the girl-child and chart a good future for her. Information from FGDs revealed that culture plays very important roles in the lives of the people. Religious prescriptions were cited by male participants in the FGDs but there was a general agreement by female participants that poverty plays a major role in decisions to marry off girls early, particularly when they are withdrawn from schools for marriage, sometimes with the hope that they may continue after marriage and sponsored by the husband. This was corroborated by the quantitative data on the factors influencing the timing of marriage in the area, $47 \%$ of the respondents agreed that poverty was the major factor influencing child marriage in the area, while $21.5 \%$ and $12.5 \%$ respectively mentioned culture and religion. Gombi and surrounding communities are largely rural and there were expressions of anxiety over African Health Sciences Vol 16 Issue 4, December, 2016 
the spread of certain values from the nearby urban areas which may lead to the breakdown of long-held family and community values, the need to prevent prostitution, unwanted teenage pregnancies, childlessness and other unwholesome western values that allow what is considered unnecessary freedom for young girls. Majority (87\%) of the respondents expressed the wish to experience schooling beyond the level they presently were and their admiration for well-educated women, in terms of appearance, confidence and material possession. This was supported by the FGDs conducted.

\section{Religious leader in Lala:}

A girl must be in her husband's house before or at puberty. This is why parents give their young girls' hands in marriage at their younger ages. Education is good for girls but they must be properly married--------------if a good marriage arrangement that favours the girl and the family comes up, it is good for the girl to leave school and marry first, then continue later if the husband permits-----“"

\section{Community elder, Wushipra:}

"The main reason why parents allow their daughters to marry very early is to avoid shame; they try to avoid promiscuity which may lead to unwanted pregnancy. They prefer early marriage to our young girls becoming prostitutes. Our culture does not permit misbehavior by girls, even boys must marry early to be responsible. It is the duty of a girls's father to marry her of appropriately".

\section{Decision-making}

Decision -making on the choice and timing of marriage is the exclusive preserve of fathers in the study area as revealed by $79 \%$ of the respondents (Table 2 ) and more often than not, husbands arranged for young girls are older men within the society who can afford the bride price and other items demanded by the bride's parents.

On the women's economic status, $78 \%$ of the respondents depend on their husbands for all (Table 2) their daily needs and that of their children, even when involved in some employment, trade or farming.

Table2. Percentage Distribution of Respondents' Family and Marriage Characteristics

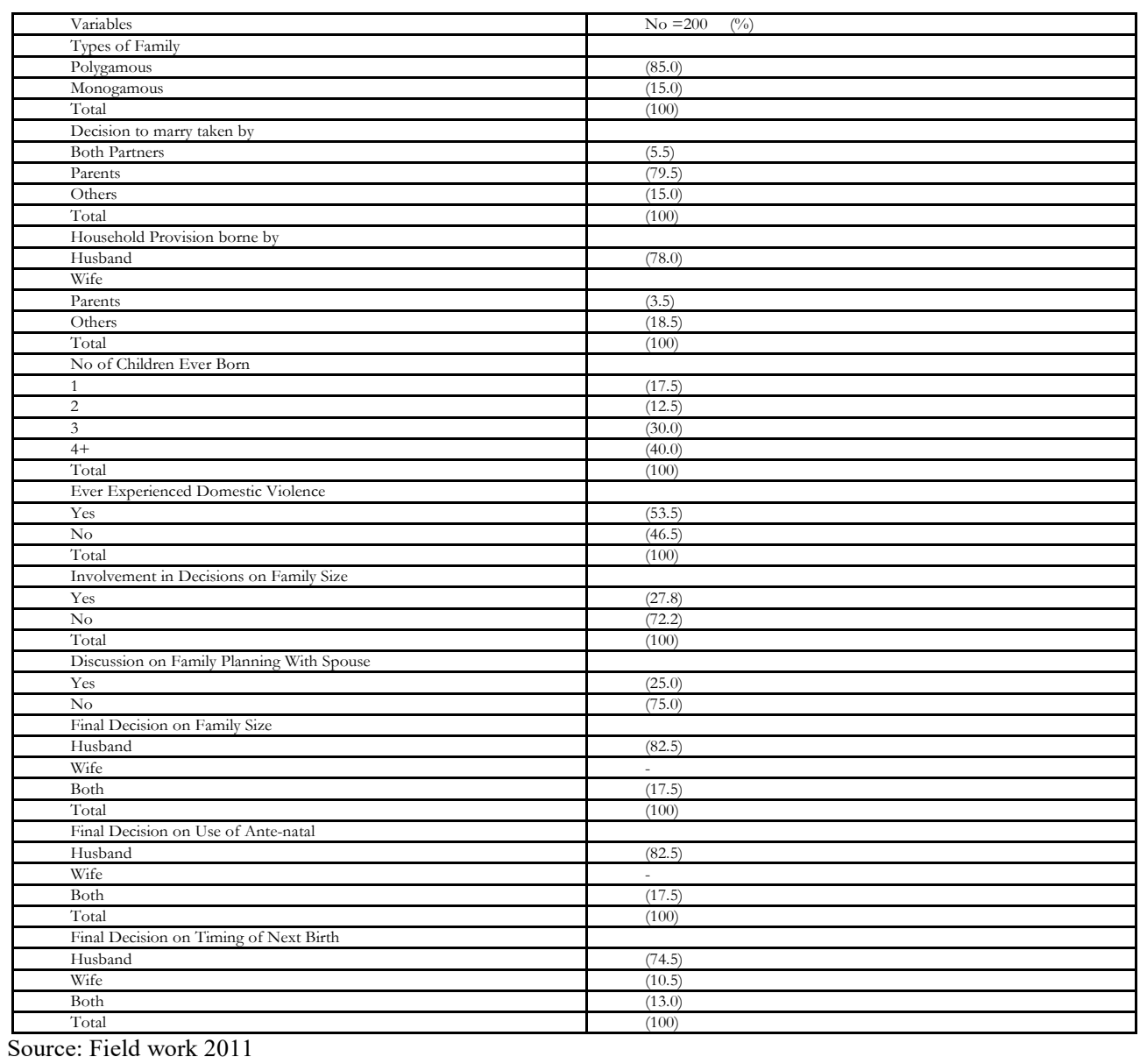


The status of women in the study area is revealed in the generally low educational attainment, low income and the pattern of family and fertility decision-making that is highly patriarchal. Majority $(82 \%)$ responded that husbands were the sole decision makers on issues of fertility and family size and use of contraception (Table 2). This is evident in the overwhelming $82.5 \%$ of the respondents that reported that husbands determined the decision to register for and timing of ante-natal care, as well as particular health facility to use, which may be heavily de-pendent on affordability. Since husbands were the main providers in the households, wives were generally very submissive as culturally expected. This was corroborated by the FGDs in which participants revealed that fertility decisions taken by husbands were sometimes injurious to the health and wellbeing of the wives and cited decisions to have another child to ensure a male child or more male children.

\section{A 24 year old, Gombi}

Since we depend on our husbands for the daily needs and they are the ones that can determine the number of children. If I have the resources (e.g. land) and I make a lot of money from it, I can say I want this number of children or this is the hospital I want to use. They are the ones that own the land and the crops, we are just assisting them to support our family.

\section{A trader (18 years), Fadchi}

It is our religion that allows husbands or the heads of the family to be the one to decide on the number of children. Even if the wife desires more children and the husband says no there is nothing she can do. Likewise if the husbands desire more children the wife can't say no to him. Male children are favoured in our culture---

\section{A housewife, Guyaku:}

It is not the fault of women not to go to the hospital, their husbands must approve of it because you can't take the decision on your own.

Only $25 \%$ of the respondents ever discussed the need for family planning and use of contraceptives with their husbands. Spousal communication on the use of contraceptives as previously revealed (NDHS, 2008) is therefore still very low. The data also revealed that spousal communication on fertility issues is very low as a result of the wide age differences between the young mothers and their husbands The FGDs revealed a general lack of confidence by respondents in articulating the issues around reproductive health issues and associated with childbearing.

\section{Maternal health risks}

The data revealed that respondents commenced childbearing between 14 and 18 years of age and 71\% had experienced at least one serious pregnancy or birth-related health problem which include excessive bleeding during labour $(19.0 \%)$, obstructed and/or prolonged labour $(49.0 \%)$, frequent miscarriages $(12.0 \%)$ and pro longed sickness after childbirth $(20 \%)$ as shown in Table 3.

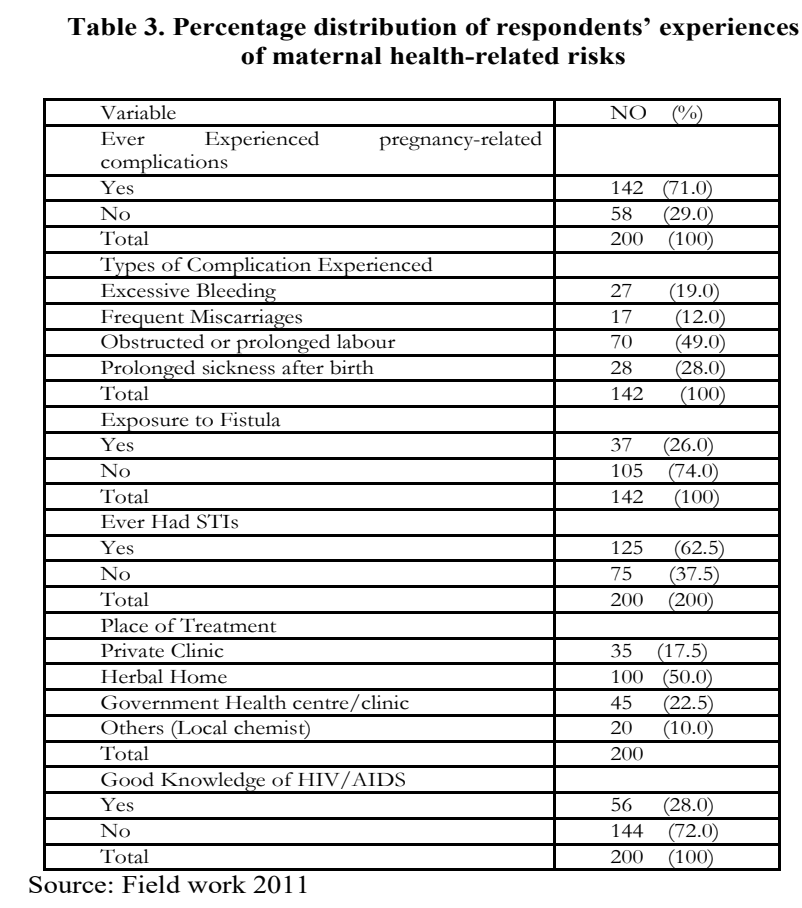


In addition to these, of those that had experienced various health complications, $37(26 \%)$ had been exposed to the risk of vesico-vagina and recto-vigina fistula and were at various stages of treatment. This and discussions in the FGDs revealed that maternal morbidity is very high among the young mothers. The uptake of opportunities for antenatal and post-natal care was reported-ly low among women due to distance from the facilities, cost, husband's attitude and ignorance. Birth-spacing is not deliberately practiced and contraceptive use is almost non-existent. While there were no locally collated figures, health personnel also confirmed a high and increasing frequency of maternal deaths involving young mothers, in and outside health facilities in the study area ${ }^{12,14,17}$.

\section{A nurse, Gombi:}

"Most of the cases we witness in the health facilities are prolonged labour, VVF and excessive bleeding. Some of these women are too young for childbearing but because of our culture and religion there is nothing we can do, we are educating them still we still have new cases every day. Sexually Transmitted Infections are very common around here but many are treated at the local chemists and herbal clinics rather than in the hospitals because of shame. We know that the most important issue is the immaturity of their bodies---that is the risk".

\section{A civil servant, Gombi}

"It is prolonged and obstructed labour that is more common in this area, with excessive bleeding. It has led to loss of many girls in our community. Some of these women are not well informed about the pregnancy complications. Some of them will not attend anti-natal clinic. They are too young and not yet ripe for childbearing but are married and expected to have children. They are also children"

\section{A full housewife, Misamba:}

Miscarriage and excessive bleeding are very common pregnancy complications in our community. Also prolonged labour mainly because pregnant women do not register early for ante natal care because the young ones don't have money they don't know when its appropriate to do so.

\section{A nurse/midwife, Balwhona:}

"We are used to complications in this health facilities, this was common among young girls, who married before age 18 years. Some of them will not come to the health facilities for anti-natal until it has resulted to complications - sometimes it might result to death. We have witnessed several deaths of young girls that are wives and too young to safely deliver their children"

\section{A medical doctor, Gombi:}

Majority of the complications we have handled were as a result of early marriage and their negligence of not attending anti-natal for proper medical advice. VVF cases are also common in this area, but we are trying our best to educate them.

The sample of young early-married mothers was analysed for differentials in experiences of pregnancy-related complications across categories as shown in Table 5.

Table 5. Analysis of selected variables and maternal health risks (ever had complications?).

\begin{tabular}{|c|c|c|c|c|c|}
\hline \multicolumn{6}{|l|}{ Variables } \\
\hline & & \multicolumn{4}{|c|}{ Ever had complication } \\
\hline Religion & & No & $\%$ & No & $\%$ \\
\hline Christianity & & 57 & 69.5 & 22 & 30.5 \\
\hline Islam & & 82 & 72.0 & 36 & 28.0 \\
\hline + Total & & 142 & 71.0 & 58 & 29.0 \\
\hline \multicolumn{6}{|l|}{$2 \mathrm{P}$ Valuc $=0.0052$} \\
\hline \multicolumn{6}{|l|}{$\mathrm{Agc}$} \\
\hline $15-19$ & & 41 & 75.0 & 14 & 25.0 \\
\hline $20-24$ & & 101 & 69.6 & 44 & 20.4 \\
\hline +Total & & 142 & 71.0 & 58 & 29.0 \\
\hline \multicolumn{6}{|l|}{$\mathrm{V}_{2}^{2} \mathrm{P}$ Valuc $=0.0041$} \\
\hline \multicolumn{6}{|l|}{ Educational Level } \\
\hline $\begin{array}{l}\text { Primary } \\
\text { Completed) }\end{array}$ & Not & 50 & 78.0 & 14 & 22.0 \\
\hline Primary (Completed) & & 38 & 67.8 & 28 & 32.2 \\
\hline Secondary & & 34 & 61.6 & 26 & 38.4 \\
\hline Post Sccondary & & 10 & 50.0 & 10 & 50.0 \\
\hline +Total & & 142 & 100 & 58 & 29.0 \\
\hline
\end{tabular}




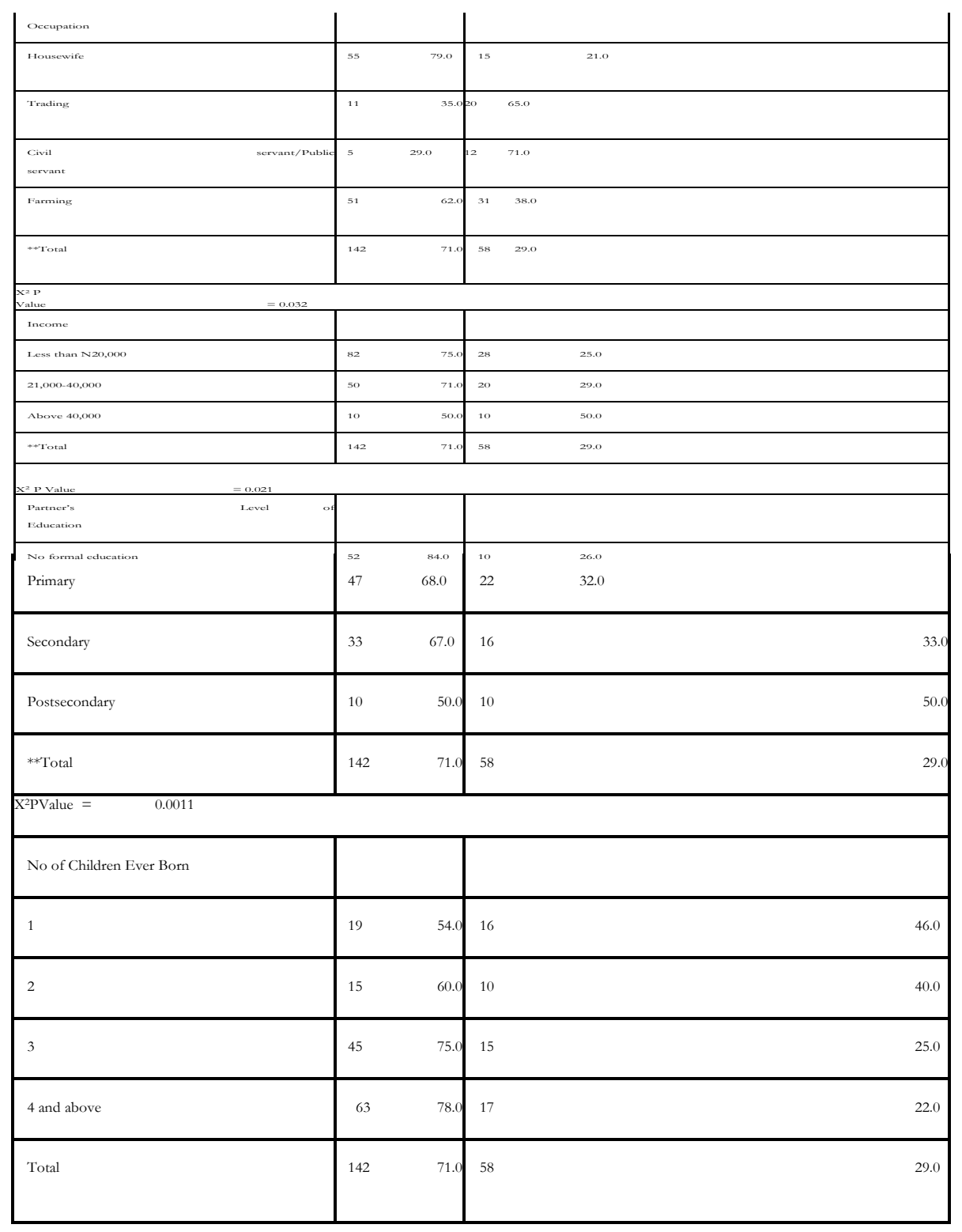

** Excluding Non-Response Category

Religious affiliation had minimal impact on the occurrence of pregnancy complications as slightly more Muslims (72\%) than Christians (69\%) had experienced complications. However, the FGDs and in-depth interviews with religious and community leaders revealed that early marriage of before 18 years is the norm in the study area but child marriages are conducted mostly among Muslims because the religion permits it, with caution.

The experience of serious pregnancy-related complications decrease with increasing exposure to educational opportunities with more respondents with primary level (completed, 67.8\%; not completed, $78.0 \%$ ) education reporting complications, compared to those with secondary $(61.6 \%)$ and post secondary $(50 \%)$ levels of education. Similarly, respondents' husbands' level of education was found to be associated.
Of the respondents that had experienced complications, more husbands had no formal education $(84 \%)$ or primary level education, $(68 \%)$ compared with those that had secondary $(67.0 \%)$ and post secondary (50.0\%) levels. The data (Table 5) also show that pregnancy-related complications were reported more among respondents aged $15-19$ years $(75 \%)$, low income (less N20,000.00 per month), full housewives $((79.0 \%)$ and farmers $(62.0 \%)$ than among those aged $20-24$ years $(69.6 \%)$, high income (N40,000.00 + per month), traders $(35.0 \%)$ and civil servants in salaried employment (29.0\%). Significantly, experiences of pregnancy-related complications increase with increasing number of children of the respondents from one $(54 \%)$ to at least four children $(78 \%)$ in the study area. The data therefore reveal that level of education of respondents and their husbands, income of respondents,

African Health Sciences Vol 16 Issue 4, December, 2016 
age of respondents, number of children ever born and to a lesser extent, religion influence exposure to maternal health risks of young mothers that married very early in the study area.

The outcome of logistic regression (Table 6) of selected variables and Ever Had Pregnancy Complications further corroborated the findings and revealed that respondents aged 15-19 years are (OR 1.211, CI 1.328-1.504, P<0.005) more likely to experience pregnancy complications than those aged 20-24 years. With the level of education of the respondents, those with primary education (completed and non-completed) are contraceptives (OR 4.11, CI 0.505-1.831, P<0.001)and (OR 2.43, CI 0.367-1.910, $\mathrm{P}<0.005)$ respectively more likely to experience compli- cations than those in other categories. This is probably because those with little education before marriage may be unable or poorly equipped to take appropriate reproductive health decisions that are important in reducing pregnancy-related complications. Low empowerment, indicated by low income and low decision-making power is significantly associated with the likelihood of experiencing pregnancy complications in the study area as those with low empowerment are (OR 3.962, CI 0.937-1.083, $\mathrm{P}<0.005)$ more likely to experience complications when compared with other categories. Number of children is also another significant factor identified in the analysis, it was revealed that ever-experienced complications may likely increase with the number of children. This is an interesting finding in this study, particularly with low contraceptive use.

\begin{tabular}{|c|c|c|c|c|}
\hline Variables & $\mathrm{B}$ & OR & $95 \% \mathrm{CI}$ & P Value \\
\hline \multicolumn{5}{|l|}{ Age } \\
\hline $15-19$ & 0.19 & 1.211 & $1.328-1.504$ & 0.020 \\
\hline $20-24$ & 1.00 & $\mathrm{RC}$ & & \\
\hline \multicolumn{5}{|l|}{ Level of Education } \\
\hline Primary Completed & 1.43 & 4.11 & $.505-1.831$ & .018 \\
\hline Primary Non Completed & .9061 & 2.43 & $.367-1.910$ & 0.002 \\
\hline Secondary & .337 & 1.400 & $.670-2.928$ & .371 \\
\hline Post secondary & 1.00 & $\mathrm{RC}$ & & \\
\hline \multicolumn{5}{|l|}{$\begin{array}{l}\text { Level of Empowerment } \\
\text { (Decision Making) }\end{array}$} \\
\hline High Empowerment & 1.00 & $\mathrm{RC}$ & & \\
\hline Low Empowerment & 1.374 & 3.961 & $.937-1.083$ & 0.039 \\
\hline \multicolumn{5}{|l|}{ Occupation } \\
\hline Farming & -0.1579 & 0.8162 & $.70-.94$ & 0.771 \\
\hline Trading & -0.2127 & 0.8084 & $0.67-1.04$ & 0.201 \\
\hline Civil/public servant & -.1579 & 0.8562 & $0.87-1.48$ & 0.304 \\
\hline Housewife & 1.00 & $\mathrm{RC}$ & & \\
\hline \multicolumn{5}{|l|}{ No of Children } \\
\hline \multicolumn{5}{|c|}{1} \\
\hline$\frac{2}{2}$ & -0.3486 & 0.7057 & $0.123-4.349$ & 0.003 \\
\hline$\frac{5}{3}$ & -0.128 & 0.028 & $0.21-0.37$ & 0.046 \\
\hline 4 and above & 0.04 & 1.04 & $0.81-1.27$ & 0.018 \\
\hline \multicolumn{5}{|l|}{ Years of Marriage } \\
\hline Less than 5 years & 0.9061 & 2.475 & $0.230-.283$ & 0.012 \\
\hline 5-9 Years & .00231 & 1.02 & $0.68-1.05$ & 0.435 \\
\hline 10 years and above & 1.00 & $\mathrm{RC}$ & & \\
\hline \multicolumn{5}{|l|}{ Income } \\
\hline Less than $\mathrm{N} 20,000$ & 0.948 & 2.58 & $0.94-2.19$ & 0.216 \\
\hline $21,000-40,000$ & 0.97 & 2.63 & $1.40-4.89$ & 0.286 \\
\hline Above 40,000 & 1.00 & $\mathrm{RC}$ & & \\
\hline
\end{tabular}

\section{Maternal health-seeking behaviour}

Place of delivery is one of the factors that influence maternal deaths and $28 \%$ of the respondents delivered their last baby at home while $23 \%$ delivered at the homes of traditional birth attendant. From the survey, 33\% of the respondents indicated that the health facilities were far, more than $5 \mathrm{kms}$ from their homes and this may be one of the reasons for none use of the health facility. Participants from the FGDs expressed confidence in nurses, midwives and traditional birth attendants compared to doctors. This was collaborated by the responses in table 4. Delay in seeking medical treatment is one of the factors mentioned among the FGDs participants as a cause of maternal death and complications in the study area. This may be as a result of the revelation that decisionmaking regarding medical treatment is the responsibility of husbands and only 17.5\% (Table 4) of the respondents reported their ability to decide on their medical treatment. Only $43.5 \%$ of the respondents used ante-natal care regularly while $11 \%$ indicated that they had never attended anyante-natal prior to their delivery. 
Table 4. Percentage distribution of respondents maternal health-seeking behaviour

\begin{tabular}{|l|l|}
\hline Variables & NO $=\mathbf{2 0 0}$ \\
\hline Place of Delivery of last Birth & $(28.0)$ \\
\hline Respondents Home & $(20.0)$ \\
\hline Govt Hospital & $(19.0)$ \\
\hline Govt. Health Centre & $(10.0)$ \\
\hline Private Hospital/Clinic & $(23.0)$ \\
\hline Traditional Birth Attendant & \\
\hline Total & \\
\hline $\begin{array}{l}\text { Type of Health Personnel for Delivery of last } \\
\text { child }\end{array}$ & $(10.0)$ \\
\hline Doctor & $(25.0)$ \\
\hline Nurse/midwife & $(15.0)$ \\
\hline Auxillary midwife & $(17.0)$ \\
\hline CS health professional & $(30.0)$ \\
\hline Traditional Birth attendant & $(3.0)$ \\
\hline Relative, Friend & $(100)$ \\
\hline Total & \\
\hline $\begin{array}{l}\text { Capacity to decide on Medical treatment for } \\
\text { self/children }\end{array}$ & $(17.5)$ \\
\hline Yes & $(80.0)$ \\
\hline No & $(2.5)$ \\
\hline Depends & $(100)$ \\
\hline Total & \\
\hline Proximity of Health Facilities & $(23.0)$ \\
\hline $0-2 \mathrm{~km}$ & $(43.5)$ \\
\hline 3-4km & $(33.5)$ \\
\hline More than 5km & $(100)$ \\
\hline Total & $(11.0)$ \\
\hline Use of ante-natal care & $(43.5)$ \\
\hline Never & $(45.5)$ \\
\hline Always & $(100)$ \\
\hline Sometimes & \\
\hline Often & \\
\hline Total & \\
\hline & \\
\hline
\end{tabular}

\section{A medical personnel, Gombi (IDI)}

"We don't have enough hands in this hospital but most of these women, particularly the young ones will not report at the bealth facilities on time until their cases are getting out of hands. With no bistory of the pregnancies, delays are caused in diagnosis prior to treatment---Also many women are referred to this facility from surrounding villages and sometimes they are very young for childbearing and bave not been to any facility for ante-natal care so it could be too late to save them and the babies" 


\section{Discussion}

This study has established that girls in Gombi locality are facing significant cultural and social barriers to living wholesome and healthy lives that are often strengthened by religious prescriptions on marriage. These include the facts that their marriages were arranged without their consent, the opportunities for schooling were either disrupted or not utilized at all, they were made to commence sexual relations and subsequent childbearing early, they were exposed fully to various reproductive health risks as shown in this study. Another cultural factor revealed in the study is the issue of patriarchy, husbands have the final say on almost all the household decisions including the respondents' health issues.

This may be one of the reasons for the delay in seeking medical care as reported among the medical health officials who participated in the in-depth interview. Haberland, Nicole, Eric. Chong, and. Bracken. (2006) have revealed that girls married at a very younger age experience social, personal and psychological challenges when compared with those who marry latter. There is also greater control by their husbands with restriction on movement, ability to seek health care and family planning services, limited capacity to earn independent income and paid labour force. Financially, theydepend on their husbands and unable to ask their partners to go for test, use contraceptives or abstain from sex even when they know their partners are infected. The notion of good reproductive health encompasses all aspects of the reproductive process including the right to engage in sexual relations and to decide when to have children and these are the rights not accessible to the young women in the study area.

Earlier findings ${ }^{18,4}$ revealed that child brides are likely to commence childbearing early and there is a strong correlation between the age of mother and maternal morbidity. More than two thirds of the respondents indicated that they have experienced at least one the complications during their life births. Some of the complications me tioned in this study include; prolonged and obstructed labour which may lead to hemorrhage, excessive bleeding and prolonged sickness after birth. This reaffirms the impact of child marriage on the health of the mothers. Previous studies linked child marriage with some health consequences such as, Cervical Cancer, VVF, genital ulcer etc ${ }^{19,20}$. These girls are expected to prove their fertility immediately they are married off which often results into pregnancies a stage they are not prepared for, eventually leading to maternal and newborn morbidity. Girls aged 14 years and younger run a risk of complication in pregnancy and child birth when compared with those of older $\operatorname{ages}^{21}$.

Poverty has also been shown to be at the core of the way young girls are regarded as economic burden and quickly married off to alleviate household expenses as reported among the FGDs participants in the study area. In these communities, educational and economic opportunities available to girls are few and girls are often quickly married off to protect them as well as improve the economic well- being of the family. Considerations for family honour also put pressure on families to marry off young daughters, to avoid embarrassment and shame that may come with loss of virginity and unwanted pregnancies as they grow up. Early marriage invariably confines young girls to a life of poverty, in a cycle that is often difficult to break and significantly deprive them of freedom and entitlements to life. A study reveals that girls are viewed as economic burden and marrying them off is a way to alleviate household expenses ${ }^{22}$. The practice of child marriage dooms girls and women to a life of poverty. Another strong factor identified in the study is the issue of promiscuity among the girls as a strong rea-sons for their early marriage. Parents believed that instead of bring shame to the family it is better to allow suit-or to come for them. Studies have shown that girls who married early are more likely to be infected with sexually transmitted infections especially HIV and human papilloma virus (HPV). Evidences from sub-Saharan African countries revealed that half of the married girls are more likely to be infected with HIV than the unmarried ${ }^{3,23}$

The study also affirmed the significant relationship between education and pregnancy complication. Those who have higher education are less likely to have complications. Participants from the FGDs and IDIs explained that those with higher education have knowledge about signs of pregnancy complications and they can quickly access health facilities. More than two-thirds of the respondents in the study area delivered outside government hospitals and clinics, this is also a point that can influence the high maternal mortality and morbidity in the area. In her study of utilization of delivery services in Ilesa, Nigeria observed that high stillbirth and early neonatal mortality rate have been long associated with unattended deliveries compared with hospital-based deliveries ${ }^{24}$. 
Those with post-secondary education also de-lay their marriage and have the ability to make choices and this was confirmed by the FGD participants. It was stated that schooling helps girls achieve ambitions and gives them skills to discuss who and when they will marry $25,26,27,28$

Behind the practice of child marriage is a failure to guarantee child and young people's rights, manifested by denial of education, low status, deep poverty and restricted mobility. While the Nigerian Child is supposed to be protected by a well articulated legal framework earlier outlined in this paper, it is evident that in practice this is not so and there is a need to engage social and cultural norms surrounding the practice of child marriage.

The issues of legal sanctions are desirable but complicated as the laws of the country exist alongside customary and religious laws on marriage. Country laws are also not applicable to customary marriages. ${ }^{29}$ Within the context of poor registration of marriage and failure to apply recommended sanctions to law breakers (parents, spouses, officials etc), child brides are generally left unprotected. It is for these that in Nigeria, inconsistencies exist between the legal minimum age at marriage, which is 21 years and actual practice, as marriages of children as young as 7 to 10 years were reported in the FGDs conducted in few communities in the study area.

\section{Conclusion}

Initial concerns about child marriage centred on its contributions to rapid population growth, as early childbearing, in the absence of contraception results in large family sizes. However, in the latter part of the $20^{\text {th }}$ Century, advocates of safe motherhood and adolescent health turned attention to child marriage, emphasizing the vulnerability of young girls to HIV/AIDS, STIs and other serious health issues. Beyond this, however, and more recently, attention has further shifted to the need for widespread education for girls and its benefits, a situation that necessitated greater focus on child marriage and the exclusion of girls from schools within a rights-based approach. In the context of widespread HIV/AIDS, very high maternal mortality and growing sexual violence against girls within permissive traditional practices, the demographic and health implications of early marriage as practised in Gombi are grave for Nigeria.
This study has identified the negative impact of early marriage on young women in Gombi, expressed in form of high maternal morbidity through various pregnancy complications in the study area. With this, it is clear that the practice of child marriage in the study area and in other parts of Nigeria is directly impeding the ability of the country to achieve six (6) of the Millenium Development Goals, which are those of eradicating extreme poverty and hunger, achieving Universal Primary Education, promoting gender equality and empowering women, reducing child mortality, improving maternal mortality and combating HIV/AIDS, cervical cancer, sexually transmitted diseases, VVF, malaria and other communicable diseases by 2015 .

Progress in health and gender matters towards the achievement of MDGs has been scored low in Nigeria. Strategic interventions planned for gender issues, infant and maternal health, HIV/AIDs, malaria, tuberculosis and primary health and implemented since 2000 have failed to yield any appreciable results and the government at all levels are being pressured to increase allocation of resources to the sectors to ensure an overall progress in the wellbeing of the population. While increase in commitment and funding are important, there is an urgent need to refocus the development lens in Nigeria to a critical and crosscutting issue as child marriage, the reduction of which can speed up the achievement of the MDGs, if not by 2015, in as short a time as possible. There is an urgent need to focus on the cultural traps to which the practice of child marriage has confined girls in Gombi and other parts of the country, through renewed commitment to compulsory education beyond primary school level for girls, enforcement of legislation and commitments to uphold the fundamental rights of the child. In particular, men, in their capacity as fathers, community and religious leaders must be targeted for change, given their roles as custodians of tradition and decision-makers on marriage and family matters. The several elements of marriage (choice, consent, timing, etc) and maternal health must be understood afresh as entitlements and the freedom associated with them must be granted to every citizen.

\section{Coflict of interest}

None to delcare. 


\section{References}

1. Akpan Eno Obang. Early Marriage in Eastern Nigeria and the Health Consequences of Vesico- Vagina Fistulae (VVF) Among Young Mothers. Gender and Development, $O x$ fam GB 2003 Vol 11, No 2, July. doi 10.1080/741954319 2. Bamigbose, O. Legal and Cultural Approaches to Sexual Matters in Africa: The Cry of the Adolescent Girl”, The University of Miami International and Comparative Law Review, Special Issue 2001 Vol. 10; pp 127-144.

3. Bamigbose O. "Customary Law Practice and Violence Against Women: The Position Under the Nigeria Legal System" in Proceedings of the Women's World 2002, Kampala.

4. Clark S, Bruce J, Dude A . Protecting young women from HIV/AIDS: the case against child and adolescent marriag . Int Fam Plan Perspect, 2006 Vol 32:79-88. PMID- 16837388. Nigeria Child Right Act 2003

5. Effah Josephine . Modernized Slavery; Child Trade in Nigeria", Constitutional Rights. Project 1996 , Lagos.

6. Esimai OA, Ojo OS, Fasubaa OB. Utilization of approved health facilities for delivery in Ile-Ife, Osun State, Nigeria. Niger J Med. 2002 Oct-Dec;11(4):177-9 PMID18072450. Folasade Iyun. Inequalities in health care in Ondo State, Nigeria. Health Policy and Planning; 1998 3(2): 159-163

7. Forward. Safeguarding Rights and Dignity - Child Marriage and Forced Marriage 2008 .

8. Gonyok Rita.K: The Challenge of Early Marriage on the Girl Child; National Press Centre Abuja 2006

9. Haberland, Nicole, Eric L. Chong, and Hillary J. Bracken. A world apart: the disadvantage and social isolation of married adolescent girls". Brief based on background paper prepared for the WHO/UNFPA/Population Council Technical Consultation on Married Adolescents. 2006 New York: The Population Council.

10. International Planned Parenthood Federation, United Nations Population Fund, and Global Coalition on Women and AIDS. Ending child marriage: a guide for global action. London: IPPF 2005 .

11. International Center for Research in Women . Too young to wed: education \& action toward ending child marriage. Washington DC: ICRW 2005.

12. ICRW. How to End Child Marriage(2007). Washington DCICRW Solutions to End Child Marriage (2011). 13. What the Evidence Shows Immigration and Refugee Board of Canada (IRBC) Nigeria: Forced Marriage among the Yoruba, Igbo and Hausa- Fulani. Prevalence,
Consequences for a woman or Minor who refuse to participate in the Marriage; Availability of State Protection 2006.

14. Laga M, Shartlander B, Pisani E, Sow P, Carael M. To stem HIV in Africa, prevent transmission to young women. AIDS. 2001;15:931-4. DOI PubMed.

15. Jenson and Thornton . Early Marriage in the Developing World Gender and Development, 2003 vol 11(2), pp 9-19.

16. Lloyd, C. B (ed). Growing Up Global; The Changing Transistor to Adulthood in Developing Countries, Washington D. C. The National Academy Press 2005. Marriage Act Chapter 218: Law of the Federation of Nigeria 1990. 17. Nayak, Bimal Kanta Child Marriage and Its Consequences in Ethiopia. Journal of School Social Work 2014 vol 11(07)

18. Nigeria Demographic Health Survey ( 2008): The 2008 Nigeria Demographic and Health Survey NPC/ Measures DHS.

19. Nour Nawal M. Emerging Infectious Diseases. 2006 Nov; 12(11): 1644-1649. doi: 10.3201/eid1211.060510

Olateru- Olagbegi Bisi and Biola Akiyode Afolabi . Actual Women Situation in Nigeria. WILDAF Women Law and Development in Africa 2004.

20. Population Council. Population Briefs: Reports on Population Council Research 200511 (1). New York, The Population Council.

21. Raj A, Saggurti N, Balaiah D, Silverman JG. Prevalence of child marriage and its effect on fertility and fertility-control outcomes of young women in India: a cross-sectional, observational study. Lancet, 2009 373:1883-1889 doi10.1016/S0140-6736(09)60246-4.

22. Santhya KG, Ram U, Acharya R, Jejeebhoy SJ, Ram F, Singh A "Associations between early marriage and young women's marital and reproductive health outcomes: evidence from India". Int Perspect Sex Reprod Health 2010, 36:132-139DOI: 10.1363/3613210

23. Salako LA. Evaluation of clinical efficacy and safety of Halofantrine in falciparum malaria in Ibadan, Nigeria”. Trans-R-Soc-Tropical Medicine and Hygine 1990 84: 644-647 doi: 10.1016/0035-9203(90)90132-X

24. Ogunlesi Tinuade A.. The Pattern Of Utilization Of Prenatal And Delivery Services In Ilesa, Nigeria. The Internet Journal of Epidemiology. $2005 \mathrm{Vol} 2$ (2)

25. Haberland, Nicole, Eric L. Chong, and Hillary J. Brack-en. A world apart: the disadvantage and social isolation of married adolescent girls". Brief based on 
background paper prepared for the WHO/UNFPA/ Population Coun-cil Technical Consultation on Married Adolescents. 2006. New York: The Population Council 26. Gonyok Rita.K: The Challenge of Early Marriage on the Girl Child; National Press Centre Abuja 2006 27. Raj A, Saggurti N, Balaiah D, Silverman JG. Prev alence of child marriage and its effect on fertility and fertility-control outcomes of young women in In-dia: a cross-sectional, observational study. Lancet, 2009 373:1883-1889 doi10.1016/S0140-6736(09)60246-4.
28. Santhya KG, Ram U, Acharya R, Jejeebhoy SJ, Ram F, Singh A "Associations between early marriage and young women's marital and reproductive health outcomes: evidence from India". Int Perspect Sex Reprod Health 2010, 36:132-139DOI: $10.1363 / 3613210$

29. Law of the Federation of Nigeria 1990 Marriage Act Chapter 218:

30. WHO. The World Health Report 2006 - Working Together for Health. Zozulya . Maternity Mortality in Nigeria; An Indicator of Women's Status, 2001 CAI 